\title{
Hot spring bathing is associated with a lower prevalence of hypertension among Japanese older adults: A cross-sectional study in Beppu
}

Satoshi Yamasaki ( $\nabla$ yamas009@gmail.com )

Kyushu University Beppu Hospital

Tomotake Tokunou

Kyushu University Beppu Hospital

Toyoki Maeda

Kyushu University Beppu Hospital

Takahiko Horiuchi

Kyushu University Beppu Hospital

\section{Research Article}

Keywords: hypertension, hot spring bathing, nighttime, older

Posted Date: February 23rd, 2022

DOI: https://doi.org/10.21203/rs.3.rs-1342535/v1

License: (a) (i) This work is licensed under a Creative Commons Attribution 4.0 International License.

Read Full License 


\section{Abstract}

Background: Hot spring bathing is practiced to manage various diseases, including hypertension. We investigated the preventive effects on hypertension of hot spring bathing for older adults in a data analysis using responses to a previous questionnaire with the aim to identify a novel approach in the prevention and management of hypertension.

Methods: Among 10428 adults aged $\geq 65$ years, we assessed the hot spring bathing habits in the 4001 subjects with a history of hypertension. Odds ratios (OR) with $95 \%$ confidence intervals (Cls) were calculated using a multivariable logistic regression model for the history of hypertension.

Results: In a multivariable logistic regression model, age ( $\geq 85$ years; $\mathrm{OR}, 1.410 ; 95 \% \mathrm{Cl}, 1.180-1.690$ ), history of arrythmia (OR, 1.580; $95 \% \mathrm{Cl}, 1.380-1.820)$, stroke (OR, 1.590; 95\% Cl, 1.280-1.980), gout (OR, $1.900 ; 95 \% \mathrm{Cl}, 1.540-2.330)$, diabetes mellitus (OR, 1.470; 95\% Cl, 1.310-1.650), hyperlipidemia (OR, $1.680 ; 95 \% \mathrm{Cl}, 1.490-1.910)$, renal disease (OR, 1.500; $95 \% \mathrm{Cl}, 1.220-1.860)$ chronic hepatitis (OR, 0.648; $95 \% \mathrm{Cl}, 0.494-0.849)$, and hot spring bathing for $20-29 \mathrm{~min}(\mathrm{OR}, 0.817 ; 95 \% \mathrm{Cl}, 0.715-0.934)$ and at 19:00 or later (OR, $0.884 ; 95 \% \mathrm{Cl}, 0.715-0.934$ ) were independently and significantly associated with hypertension during the lifetime.

Conclusions: These results support our hypothesis that habitual nighttime hot spring bathing is associated with improved hypertension control. The findings suggest that nighttime hot spring bathing might help in preventing hypertension owing to chronic stress-induced sleep disturbance in adults aged $\geq 65$ years.

\section{Background}

Hypertension is the leading reason for visiting a hospital and for the long-term use of prescription medications $[1,2,3]$. In Japan, $\geq 60 \%$ of men aged $\geq 50$ years and of women aged $\geq 60$ years had hypertension in 2016 [4]. In the United States, although the proportion of adults with blood pressure above the target increased from $39-53 \%$, the proportion of adults with a recommendation for antihypertensive medication increased from 34-36\%, according to pooled data from 2011 to 2014. Most patients classified as above goal require nonpharmacologic intervention as initial therapy [2]. Additionally, owing to multiple stressors encountered within their occupation, groups including military personnel, firefighters, and police officers have an elevated risk for the development of cardiometabolic diseases such as atherosclerosis [5], heart disease [6] and sudden cardiac death [7], which are related to hypertension [8],

Hot spring bathing has expanded globally from Japan and Asia. Maeda et al. reported preventive effects on the occurrence of hypertension in older women [9]. However, details regarding the relationship between hot spring bathing and hypertension remain unknown. 
The aim of this retrospective study was to investigate the preventive effects on hypertension of hot spring bathing for older adults in a data analysis using responses to a previous questionnaire with the aim to identify a novel approach in the prevention and management of hypertension.

\section{Methods}

\section{Participant selection}

We retrospectively reviewed data from a questionnaire survey conducted in 2011 with 11,146 responses from individuals aged $\geq 65$ years who were living in Beppu city [9]. In that year, there were 34,465 residents of Beppu city in the age group $\geq 65$ years. Questionnaires regarding hot spring bathing habits and disease history were randomly sent to 20,000 of these residents. We analyzed responses from a total of 10,429 survey participants regarding age, sex, disease history, and hot spring bathing habits (Table 1 ). 
Table 1

Characteristics of survey respondents

\begin{tabular}{|c|c|c|c|c|}
\hline \multirow{2}{*}{\multicolumn{2}{|c|}{ Characteristic }} & Total & Hypertension & \\
\hline & & $n=10428$ & $n=4001$ & $\mathbf{P}$ \\
\hline \multicolumn{5}{|l|}{ Age, n (\%) } \\
\hline \multicolumn{2}{|c|}{$65-69$ years old } & $3121(29.9)$ & $1072(26.7)$ & $<0.001$ \\
\hline \multicolumn{2}{|c|}{ 70-74 years old } & $2898(27.7)$ & $1064(26.6)$ & \\
\hline \multicolumn{2}{|c|}{$75-79$ years old } & $2514(24.1)$ & 1019 (25.5) & \\
\hline \multicolumn{2}{|c|}{ 80-84 years old } & $1265(12.1)$ & $573(14.3)$ & \\
\hline \multicolumn{2}{|c|}{$\geq 85$ years old } & $630(6.0)$ & $263(6.8)$ & \\
\hline \multirow[t]{2}{*}{ Sex, n (\%) } & Male & $4471(42.8)$ & $1764(44.1)$ & 0.048 \\
\hline & Female & $5957(57.1)$ & $2237(55.9)$ & \\
\hline \multicolumn{5}{|c|}{ Disease history, n (\%) } \\
\hline \multicolumn{2}{|l|}{ Cancer } & $1163(11.1)$ & $431(10.8)$ & 0.346 \\
\hline \multicolumn{2}{|l|}{ Depression } & $219(2.1)$ & $88(2.2)$ & 0.625 \\
\hline \multicolumn{2}{|c|}{ Ischemic heart disease } & $724(6.9)$ & $327(8.2)$ & $<0.001$ \\
\hline \multicolumn{2}{|l|}{ Arrhythmia } & $938(8.9)$ & $471(11.8)$ & $<0.001$ \\
\hline \multicolumn{2}{|l|}{ Stroke } & 354 ( 3.3$)$ & $180(4.5)$ & $<0.001$ \\
\hline \multicolumn{2}{|l|}{ Gout } & $416(3.9)$ & $230(5.7)$ & $<0.001$ \\
\hline \multicolumn{2}{|l|}{ Asthma } & 395 (3.7) & $166(4.1)$ & 0.141 \\
\hline \multicolumn{2}{|c|}{ Diabetes mellitus } & $1427(13.6)$ & $667(16.7)$ & $<0.001$ \\
\hline \multicolumn{2}{|c|}{ Hyperlipidemia } & $1154(11.0)$ & $578(14.4)$ & $<0.001$ \\
\hline \multicolumn{2}{|c|}{ Renal disease } & $373(3.5)$ & $191(4.8)$ & $<0.001$ \\
\hline \multicolumn{2}{|c|}{ Chronic hepatitis } & $267(2.5)$ & 78 (1.9) & 0.002 \\
\hline \multicolumn{2}{|c|}{ Collagen disease } & $216(2.0)$ & $86(2.1)$ & 0.710 \\
\hline \multicolumn{2}{|l|}{ Allergy } & $572(5.4)$ & $217(5.4)$ & 0.835 \\
\hline \multicolumn{5}{|c|}{ Hot spring-bathing, n (\%) } \\
\hline \multicolumn{2}{|l|}{ Frequency } & & & \\
\hline
\end{tabular}

The $p$-values were obtained using the chi-square test. 


\begin{tabular}{|c|c|c|c|}
\hline & Total & Hypertension & \\
\hline$<1 /$ month & $2924(28.0)$ & 1181 (29.5) & 0.0013 \\
\hline $1 /$ month- $1 /$ week & 356 ( 3.4$)$ & $136(3.4)$ & \\
\hline 2-3/week & 871 ( 8.3) & $361(9.0)$ & \\
\hline 4-5/week & 1394 (13.3) & $514(12.8)$ & \\
\hline Daily & $4884(46.8)$ & 1809 (45.2) & \\
\hline \multicolumn{4}{|c|}{ Duration of immersion } \\
\hline$<10 \min$ & 2645 (25.3) & 1108 (27.7) & $<0.001$ \\
\hline $10-19 \mathrm{~min}$ & $4304(41.2)$ & $1613(40.3)$ & \\
\hline $20-29 \mathrm{~min}$ & $2616(25.0)$ & 973 (24.3) & \\
\hline$\geq 30 \mathrm{~min}$ & 864 ( 8.2) & 307 ( 7.7) & \\
\hline \multicolumn{4}{|l|}{ Years of habit } \\
\hline$<10$ years & $3021(28.9)$ & $1225(30.6)$ & 0.011 \\
\hline $10-19$ years & $1324(12.6)$ & $486(12.1)$ & \\
\hline $20-29$ years & $1034(9.9)$ & $380(9.5)$ & \\
\hline $30-39$ years & $1113(10.6)$ & $406(10.1)$ & \\
\hline$\geq 40$ years & $3076(29.4)$ & $1197(29.9)$ & \\
\hline \multicolumn{4}{|l|}{ Time } \\
\hline Before 9:00 & $1272(12.1)$ & $508(12.7)$ & $<0.001$ \\
\hline $9: 00$ to $13: 00$ & 1145 (10.9) & $433(10.8)$ & \\
\hline $13: 00$ to $19: 00$ & 4087 (39.1) & 1653 (41.3) & \\
\hline $19: 00$ or after & 3925 (37.6) & $1407(52.1)$ & \\
\hline \multicolumn{4}{|l|}{ Hot spring type } \\
\hline Simple & $2193(21.0)$ & $852(21.3)$ & 0.864 \\
\hline Chloride & 1116 (10.7) & $430(10.7)$ & 0.846 \\
\hline Bicarbonate & $329(3.1)$ & $113(2.8)$ & 0.077 \\
\hline Sulfur & $87(0.8)$ & $37(0.9)$ & 0.509 \\
\hline Iron & $23(0.2)$ & $12(0.3)$ & 0.294 \\
\hline
\end{tabular}




\begin{tabular}{|llll|}
\hline & Total & \multicolumn{2}{c|}{ Hypertension } \\
\hline Sulfate & $16(0.1)$ & $8(0.2)$ & 0.441 \\
\hline Carbon dioxide & $14(0.1)$ & 2 & 0.095 \\
Acid & 1 & 1 & 0.384 \\
Aluminum & 1 & 1 & 0.384 \\
\hline The $\mathrm{p}$-values were obtained using the chi-square test. \\
\hline
\end{tabular}

The examined variables were as follows: age; sex; disease history during the lifetime including depression, ischemic heart disease, arrhythmia, hypertension, stroke, gout, asthma, diabetes mellitus, hyperlipidemia, renal disease, chronic hepatitis, collagen disease, and allergy; and hot spring bathing habits including frequency, duration of immersion, years of habitual bathing, typical time of bathing, and type of hot spring. Informed consent to participate in the study was obtained by providing participants with information on our hospital website. The study was performed in accordance with the institutional guidelines and the principles of the Declaration of Helsinki. The protocol was approved by the institutional review board.

\section{Statistical methods}

We analyzed the frequencies and descriptive statistics of participant variables. Intergroup differences in categorical variables were expressed as number and percentage. The chi-square statistical method was used for testing the relationships between categorical variables. Univariable and multivariable logistic regression models were used to determine associations between variables and the prevalence of hypertension. Covariates that were significant at $p<0.05$ in univariate analysis were included in the multivariate analysis. All tests were two-sided. We calculated $95 \%$ confidence intervals, and $p<0.05$ was considered statistically significant. Analyses were conducted using EZR (Saitama Medical Center, Saitama, Japan; http://www.jichi.ac.jp/saitama-sct/SaitamaHP.files/statmedEN.html) [10], which is a graphical user interface for R version 2.13 .0 (www.r-project.org), and a modified version of R Commander version 1.6-3 designed to add statistical functions.

\section{Results}

Overall, 4001 of 10,428 participants (38.3\%) had the prevalence of hypertension. The baseline characteristics of participants with hypertension during the lifetime are presented in Table 1. In a univariable logistic regression model, age $\geq 85$ years, female sex, arrhythmia, stroke, gout, diabetes mellitus, hyperlipidemia, renal disease, chronic hepatitis, and hot spring bathing frequency (2-3 times/week and daily), duration of immersion (10-19 min and 20-29 min), bathing time (13:00 to 19:00 and 19:00 or later), and years of habitual hot spring bathing (10-19 years) were significantly associated with influencing hypertension during the lifetime (Table 2). In a multivariable logistic regression model, age $\geq 85$ years, arrhythmia, stroke, gout, diabetes mellitus, hyperlipidemia, renal disease, chronic 
hepatitis, and hot spring duration of immersion (20-29 $\mathrm{min}$ ) and bathing time (19:00 or later) were significantly associated with the prevalence of hypertension during the lifetime (Table 2). These findings support the hypothesis that hypertension can be predicted with habitual nighttime hot spring bathing. 
Table 2

Univariable and multivariable analysis of variables influencing history of hypertension

\begin{tabular}{|c|c|c|c|c|c|c|}
\hline \multirow[b]{2}{*}{ Variable } & \multicolumn{3}{|c|}{ Univariable } & \multicolumn{3}{|c|}{ Multivariable } \\
\hline & OR & $95 \% \mathrm{Cl}$ & $p$ & OR & $95 \% \mathrm{Cl}$ & $p$ \\
\hline Age 65-69 years old & 1.000 & reference & & & & \\
\hline 70-74 years old & 1.110 & $0.998-1.230$ & 0.055 & & & \\
\hline $75-79$ years old & 0.891 & $0.747-1.060$ & 0.202 & & & \\
\hline 80-84 years old & 1.080 & $0.893-1.310$ & 0.418 & & & \\
\hline$\geq 85$ years old & 1.460 & $1.230-1.740$ & $<0.001$ & 1.410 & $1.180-1.690$ & $<0.001$ \\
\hline Sex Male & 1.000 & reference & & & & \\
\hline Female & 0.923 & $0.852-0.999$ & 0.048 & 1.030 & $0.948-1.120$ & 0.474 \\
\hline \multicolumn{7}{|l|}{ Disease history } \\
\hline Cancer & 1.000 & reference & & & & \\
\hline Depression & 0.970 & $0.733-1.280$ & 0.830 & & & \\
\hline Ischemic heart disease & 1.150 & $0.985-1.350$ & 0.076 & & & \\
\hline Arrhythmia & 1.610 & $1.400-1.850$ & $<0.001$ & 1.580 & $1.380-1.820$ & $<0.001$ \\
\hline Stroke & 1.620 & $1.310-2.010$ & $<0.001$ & 1.590 & $1.280-1.980$ & $<0.001$ \\
\hline Gout & 1.860 & $1.520-2.280$ & $<0.001$ & 1.900 & $1.540-2.330$ & $<0.001$ \\
\hline Asthma & 1.130 & $0.914-1.390$ & 0.265 & & & \\
\hline Diabetes mellitus & 1.460 & $1.300-1.630$ & $<0.001$ & 1.470 & $1.310-1.650$ & $<0.001$ \\
\hline Hyperlipidemia & 1.650 & $1.460-1.870$ & $<0.001$ & 1.680 & $1.490-1.910$ & $<0.001$ \\
\hline Renal disease & 1.520 & $1.230-1.880$ & $<0.001$ & 1.500 & $1.220-1.860$ & $<0.001$ \\
\hline Chronic hepatitis & 0.656 & $0.500-0.859$ & 0.002 & 0.648 & $0.494-0.849$ & 0.0016 \\
\hline Collagen disease & 1.030 & $0.774-1.360$ & 0.861 & & & \\
\hline Allergy & 0.942 & $0.789-1.130$ & 0.509 & & & \\
\hline
\end{tabular}

$\mathrm{OR}$, odds ratio; $\mathrm{Cl}$, confidence interval.

†Univariable or multivariable competing event statistics analyzed using a logistic regression model were applied to a positive history of hypertension. Covariates significant at $p<0.05$ in univariate analysis were included in the multivariate analysis. 


\section{Univariable}

1.000 reference

$<1 /$ month

$0.912 \quad 0.728-1.140 \quad 0.427$

1/month-1/week

2-3/week

4-5/week

Daily

Duration of immersion

$<10 \min$

1.000 reference

10-19 min

0.832

$0.753-0.918$

0.765

$0.652-0.897$

0.931

0.793-1.090

$\geq 30 \mathrm{~min}$

Time

Before 9:00

9:00 to $13: 00$

13:00 to $19: 00$

19:00 or after

Years of habit

$<10$ years

1.000 reference

$10-19$ years

0.851

$0.745-0.973$

0.017

0.884

$0.754-1.040$

$1.050 \quad 0.869-1.270 \quad 0.622$

$20-29$ years

1.040

$30-39$ years

$\geq 40$ years

1.150

$0.861-1.250$

0.706

Hot spring type

Simple

0.982

$0.982-1.350$

0.082
1.000 reference

$0.915 \quad 0.776-1.080 \quad 0.286$

$1.220 \quad 1.110-1.330<0.001$

0.884

$0.715-0.934$

0.0030
Multivariable

$0.932 \quad 0.821-1.060$

0.281

Chloride

0.977

\begin{tabular}{|cc}
\hline $0.889-1.080$ & 0.714 \\
\hline $0.858-1.110$ & 0.722
\end{tabular}

OR, odds ratio; $\mathrm{Cl}$, confidence interval.

'Univariable or multivariable competing event statistics analyzed using a logistic regression model were applied to a positive history of hypertension. Covariates significant at $p<0.05$ in univariate analysis were included in the multivariate analysis. 


\begin{tabular}{|llll|}
\hline Bicarbonate & 0.805 & $0.638-1.010$ & 0.065 \\
\hline Sulfur & 1.150 & $0.752-1.760$ & 0.515 \\
Iron & 1.590 & $0.712-3.540$ & 0.258 \\
\hline Sulfate & 1.590 & $0.595-4.240$ & 0.356 \\
Carbon dioxide & 0.265 & $0.059-1.180$ & 0.081 \\
\hline
\end{tabular}

$\mathrm{OR}$, odds ratio; $\mathrm{Cl}$, confidence interval.

†Univariable or multivariable competing event statistics analyzed using a logistic regression model were applied to a positive history of hypertension. Covariates significant at $p<0.05$ in univariate analysis were included in the multivariate analysis.

\section{Discussion}

Traditional thermal therapy and hot spring bathing have proven useful for various diseases, including hypertension [11]. We investigated the preventive effects of long-term hot spring bathing in adults aged $\geq$ 65 years. We found that age $\geq 85$ years; history of arrythmia, stroke, gout, diabetes mellitus, hyperlipidemia, and renal disease were independently and significantly associated with a higher risk of developing hypertension during the lifetime. We found that history of chronic hepatitis; and hot spring bathing duration and time were independently and significantly protective against hypertension development during the lifetime. These results support our hypothesis that habitual nighttime hot spring bathing is protective against hypertension development.

The implications of our data can be extrapolated in comparisons regarding the prevalence of hypertension according to questionnaire survey responses in adults aged $\geq 65$ years. We found that nighttime hot spring bathing, which can improve sleep disorders, might be associated with the prevention of hypertension in adults aged $\geq 65$ years. In a large-scale study among an older population, Tai et al. reported that nighttime hot spring bathing is significantly associated with shorter sleep onset latency and higher distal-proximal skin temperature gradient [12]. Sawatari et al. suggested that leg thermal therapy could improve subjective and objective sleep quality in patients with chronic heart failure [13]. The COVID19 pandemic has placed all people at risk for developing psychiatric and mental health disorders, including sleep disturbances [14]. It is therefore possible that nighttime hot spring bathing may improve sleep, with may result in improving hypertension control [15].

According to our data, age $\geq 85$ years was significantly associated with the prevalence of hypertension. Many risk factors are associated with hypertension development, such as age, obesity, family history, high-sodium diet, and physical inactivity [16, 17]. Regarding disease history, stroke [18] and renal disease $[19,20]$ are associated with hypertension. Given that health care spending on hypertension exceeded USD 70 billion in the United States between 1996 and 2016 [21], clinicians and researchers have great interest 
in proactive and preventive interventions versus reactive approaches for hypertension. In this study, we demonstrated that an alternative option for potentially improving hypertension control in adults aged $\geq$ 65 years is habitual nighttime hot spring bathing.

Stress has two components: an acute phase and a chronic phase [22]. Rozanski et al. verified a direct association between cardiovascular disease and chronic stress, which is known to modulate vascular endothelial cell function and platelet aggregation [23]. Dual stressors include psychological and physiological stressors and are known to elicit activation of the hypothalamic and sympathoadrenal axes and a subsequent greater release of stress markers such as cortisol, epinephrine, and norepinephrine, in comparison with a single stressor $[24,25]$. Increased levels of cortisol and oxidative stress in the body can upregulate several proinflammatory pathways, which can result in the development of several cardiovascular diseases including hypertension [26]. Endocrine responses to sauna bathing show that some markers of stress, such as cortisol, $\beta$-endorphins, and adrenocorticotropic hormone, respond to acute heat exposure in a highly variable manner [27]. Different results regarding the hormone response are likely owing to differences in study methods and consideration of factors such as therapy duration, time, and frequency, which were considered in our study. Therefore, revealing the cardiovascular responses will provide a more comprehensive picture of the physiological responses to hot spring bathing. Sauna baths have decreased blood pressure compared with pre-sauna measures [28]. Although brief exposures to sauna baths resulted in benefits for $<1$ hour, including reduction of blood pressure and improvement of arterial stiffness, $\geq 3$ weeks and repeated exposures upregulated enzymes and pathways, which resulted in inducing stress tolerance, stronger cellular environment, and elevated health [29]. Due to a lack of adherence to physical activity and nutrition interventions and the time pressures among individuals aged $\geq 65$ years, practical interventions that can prevent or improve hypertension, such as habitual hot spring bathing, warrant additional attention.

Our study has some limitations that should be acknowledged. First, some selection bias is expected with use of questionnaire surveys; however, bias is present owing to differences in data selection. Second, important data regarding the prevalence of hypertension was likely missing because this information was collected using self-report questionnaires. To minimize bias, we limited the inclusion criteria to age, sex, disease history, and hot spring bathing habits. Third, we have no data about the treatment and outcomes of hypertension; further studies are needed to assess the details of treatment and outcomes in patients with hypertension. Finally, the purpose of this study was to help clarify the relationship between prevention of hypertension and habitual hot spring bathing. However, it was difficult to interpret the obtained evidence, such as the interactions among duration of immersion, frequency, time, and years of habitual hot spring bathing because we did not evaluate the quality of the questionnaire data.

\section{Conclusions}

In conclusion, we found that habitual nighttime hot spring bathing was significantly associated with a lower prevalence of hypertension in older adults. It is important to prioritize clinical trials regarding the prevalence of hypertension, including identifying effective approaches to the monitoring and 
management of arrhythmia, stroke, gout, diabetes mellitus, hyperlipidemia, renal disease, and chronic hepatitis. Our findings suggest that nighttime hot spring bathing can help to reduce stress, improve sleep disorders, and reduce the incidence of hypertension.

\section{Declarations}

\section{Ethics approval and Consent to Participate}

This was a retrospective study with no experimental interventions. The study was approved by the Institutional Review Board of Kyushu University Hospital in Japan. The study was performed in accordance with the institutional guidelines and the principles of the Declaration of Helsinki. Informed consent was obtained from all individual participants included in the study.

\section{Consent for publication}

Not applicable.

\section{Availability of data and material}

We used data obtained from a questionnaire performed in 2011 in Beppu, Japan. The datasets generated and analyzed during the current study are not publicly available due to privacy and confidentiality restrictions pertaining to person-level health information. However, the dataset creation plan is available from the corresponding author on reasonable request.

\section{Competing interest}

All authors declare that they have no competing interest.

\section{Funding}

No funding or sponsorship was received for this study or publication of this article. The article processing charges were funded by the authors.

\section{Authors' Contributions}

S. Y. designed the study, analyzed the data, and prepared the manuscript. S. Y., T. T., T. M., and T. H. prepared and reviewed the manuscript. 


\section{Acknowledgments}

We thank the patients and clinical staff for their participation in the study.

\section{References}

1. Whelton PK, Carey RM, Aronow WS, Casey DE Jr, Collins KJ, Dennison Himmelfarb C, DePalma SM, Gidding S, Jamerson KA, Jones DW, MacLaughlin EJ, Muntner P, Ovbiagele B, Smith SC Jr, Spencer CC, Stafford RS, Taler SJ, Thomas RJ, Williams KA Sr, Williamson JD, Wright JT Jr.2017 ACC/AHA/AAPA/ABC/ACPM/AGS/APhA/ASH/ASPC/NMA/PCNA Guideline for the Prevention, Detection, Evaluation, and Management of High Blood Pressure in Adults: A Report of the American College of Cardiology/American Heart Association Task Force on Clinical Practice Guidelines. Hypertension. 2018;71:e13-e115.

2. Muntner P, Carey RM, Gidding S, Jones DW, Taler SJ, Wright JT Jr, Whelton PK. Potential US Population Impact of the 2017 ACC/AHA High Blood PressureGuideline.Circulation. 2018;137:109118.

3. Yoon SS, Gu Q, Nwankwo T, Wright JD, Hong Y, Burt V. Trends inbloodpressureamong adults with hypertension: United States, 2003 to 2012. Hypertension. 2015;65:54-61.

4. Hisamatsu T, Segawa H, Kadota A, Ohkubo T, Arima H, Miura K.Epidemiology ofhypertensioninJapan: beyond the new 2019 Japanese guidelines. Hypertens Res. 2020;43:13441351.

5. Joseph PN, Violanti JM, Donahue R, Andrew ME, Trevisan M, Burchfiel CM, Dorn J.Policework and subclinicalatherosclerosis.J Occup Environ Med. 2009;51:700-707.

6. Kales SN, Soteriades ES, Christoudias SG, Christiani DC.Firefighters and on-duty deaths from coronaryheartdisease: a case control study. Environ Health. 2003;2:14.

7. Yang J, Teehan D, Farioli A, Baur DM, Smith D, Kales SN.Suddencardiacdeathamongfirefighters45 years of age in the United States. Am J Cardiol. 2013;112:1962-1967.

8. Hurtubise J, McLellan K, Durr K, Onasanya O, Nwabuko D, Ndisang JF.The Different Facets of Dyslipidemia andHypertensioninAtherosclerosis. Curr Atheroscler Rep. 2016;18:82.

9. Maeda T, Mimori K, Suzuki S, Horiuchi T, Makino N.Preventive and promotive effects of habitualhotspa-bathing on the elderly in Japan. Sci Rep. 2018; 8: 133.

10. Kanda Y.Investigation of the freely available easy-to-use software 'EZR' for medical statistics. Bone Marrow Transplant. 2013; 48: 452-458.

11. Henderson KN, Killen LG, O'Neal EK, Waldman HS.The cardiometabolic health benefits of sauna exposure in individuals with high-stress occupations. A mechanistic review. Int J Environ Res Public Health. 2021;18:1105.

12. Tai Y, Obayashi K, Yamagami Y, Yoshimoto K, Kurumatani N, Nishio K, Saeki KJ.Hotwaterbathingbeforebedtimeand shorter sleep onset latency are accompanied by a higher distal- 
proximal skin temperature gradient inolderadults. Clin Sleep Med. 2021; 17: 1257-1266.

13. Sawatari H, Nishizaka MK, Miyazono M, Ando SI, Inoue S, Takemoto M, Sakamoto T, Goto D, Furumoto T, Kinugawa S, Hashiguchi N, Rahmawati A, Chishaki H, Ohkusa T, Magota C, Tsutsui H, Chishaki A.Three nights leg thermal therapy could improve sleep quality in patients with chronic heart failure. Heart Vessels. 2018; 33: 155-162.

14. Deng J, Zhou F, Hou W, Silver Z, Wong CY, Chang O, Huang E, Zuo QK. The prevalence of depression, anxiety, and sleep disturbances inCOVID-19patients: a meta-analysis. Ann N Y Acad Sci. 2021;1486:90-111.

15. Haghayegh S, Khoshnevis S, Smolensky MH, Diller KR, Castriotta RJ (2019)Before-bedtime passive body heating by warm shower or bath to improvesleep: A systematic review and meta-analysis. Sleep Med Rev 46:124-135.

16. Forman JP, Stampfer MJ, Curhan GC.Dietand lifestyle risk factors associated with incidenthypertensionin women. JAMA. 2009;302:401-11.

17. Carnethon MR, Evans NS, Church TS, Lewis CE, Schreiner PJ, Jacobs DR Jr, Sternfeld B, Sidney S.Joint associations of physicalactivityand aerobic fitness on the development of incidenthypertension: coronary artery risk development in young adults. Hypertension. 2010;56:4955.

18. Staessen JA, Fagard R, Thijs L, Celis H, Arabidze GG, Birkenhäger WH, Bulpitt CJ, de Leeuw PW, Dollery CT, Fletcher AE, Forette F, Leonetti G, Nachev C, O'Brien ET, Rosenfeld J, Rodicio JL, Tuomilehto J, Zanchetti A.Randomiseddouble-blind comparison of placebo and active treatment for older patients with isolated systolichypertension. The SystolicHypertensionin Europe (Syst-Eur) Trial Investigators. Lancet. 1997;350:757-764.

19. Coresh J, Wei GL, McQuillan G, Brancati FL, Levey AS, Jones C, Klag MJ.Prevalenceofhighbloodpressureand elevated serumcreatininelevel in the United States: findings from the third National Health and Nutrition Examination Survey (1988-1994). Arch Intern Med. 2001;161:1207-1216.

20. Bansal N, McCulloch CE, Lin F, Alper A, Anderson AH, Cuevas M, Go AS, Kallem R, Kusek JW, Lora CM, Lustigova E, Ojo A, Rahman M, Robinson-Cohen C, Townsend RR, Wright J, Xie D, Hsu CY; CRIC Study Investigators*.BloodPressureand Risk of Cardiovascular Events in Patients on Chronic Hemodialysis: The CRIC Study (ChronicRenallnsufficiency Cohort). Hypertension. 2017;70:435-443

21. Birger M, Kaldjian AS, Roth GA, Moran AE, Dieleman JL, Bellows BK.Spendingon Cardiovascular Disease and Cardiovascular Risk Factors in the United States: 1996 to 2016. Circulation. 2021;144:271-282.

22. Rohleder N.Stressand inflammation - The need to address the gap in the transition betweenacuteandchronicstresseffects. Psychoneuroendocrinology. 2019;105:164-171.

23. Rozanski A, Blumenthal JA, Kaplan J.Impact of psychological factors on the pathogenesis ofcardiovasculardisease and implications for therapy. Circulation. 1999;99:2192-217. 
24. Huang CJ, Webb HE, Evans RK, McCleod KA, Tangsilsat SE, Kamimori GH, Acevedo EO.Psychological stress during exercise: immunoendocrine and oxidative responses. Exp Biol Med (Maywood). 2010;235:1498-1504.

25. Webb HE, Weldy ML, Fabianke-Kadue EC, Orndorff GR, Kamimori GH, Acevedo EO.Psychologicalstressduring exercise: cardiorespiratory andhormonalresponses. Eur J Appl Physiol. 2008;104:973-981.

26. Pinheiro LC, Oliveira-Paula GH.Sources and effects ofoxidativestressinhypertension. Curr Hypertens Rev. 2020;16:166-180.

27. Podstawski R, Borysławski K, Pomianowski A, Krystkiewicz W, Żurek P.Endocrineeffectsof repeated hot thermal stress and cold water immersion in young adult men. Am J Mens Health. 2021;15:15579883211008339.

28. Ketelhut S, Ketelhut RG. The blood pressure and heart rate during sauna bath correspond to cardiac responses during submaximal dynamic exercise. Complement Ther Med. 2019;44:218-222.

29. Henderson KN, Killen LG, O'Neal EK, Waldman HS.The Cardiometabolic Health Benefits of Sauna Exposure in Individuals with High-Stress Occupations. A Mechanistic Review. Int J Environ Res Public Health. 2021;18:1105. 